\title{
Kimyasal Kinetik Deneylerinde V-diyagramı Kullanımının İncelenmesi*
}

\section{Halil DURAK**, Yaşar GENEL***}

Öz: Kimya konularının deneysel çalışmalarla desteklenmeden anlatılması ve anlaşılması çok güçtür. Bu nedenle teorik derslerin laboratuvar uygulamaları ile etkin bir şekilde desteklenmesi gerekmektedir.Laboratuvar dersinin etkin bir şekilde öğrenilebilmesi için deney raporlarının Vdiyagramı ile hazırlanmasının faydalı olabileceği düşünülmüştür. Bu amaçla fizikokimya laboratuvar dersinden başarıile geçmiş eğitim fakültesi kimya bolumu 4. sınıf öğrencilerinden oluşan 25 kişilik bir örneklemev-diyagramı çalışması yaptırılmıştır. Bu öğrencilerle mülakat yolu ile görüşmeyapılarak sonuçlar değerlendirilmiş ve klasik laboratuvar raporlarıyla karsılaştırıldığında diyagramınıngerçek bir öğrenme ortamı sağlayıp sağlayamadığı incelenmiştir.

Anahtar kelimeler: V-diyagramı, Fizikokimya laboratuvarı, Kimyasal kinetik,

*Yaşar GENEL Danışmanlığında Halil DURAK tarafından yapılmış Yüksek Lisans Tezidir.

** Doç. Dr. Van Yüzüncü Yıl Üniversitesi, Sağlık Hizmetleri Meslek Yüksekokulu, halildurak@yyu.edu.tr, ORCID ID: 0000-0003-3052-6751, Van.

*** Dr. Öğrt. Üyesi, Van Yüzüncü Y11 Üniversitesi, Eğitim Fakültesi, yasargenel61@hotmail.com, ORCID ID:0000-0002-0742-774X Van.

Gönderim: 11.03.2018 Kabul:25.05.2018
Yayın:25.07.2018 


\title{
Investigation of V-Diagram Usage in Chemical Kinetic Experiments
}

\begin{abstract}
Explaining and understanding chemistry topics without being supported by empirical studies is a difficulty. Therefore, theoretical courses must be supported effectively with laboratory applications.It was thought that it would be useful to prepare the experiment reports with the V-diagram so that the laboratory course can be learned effectively.Forthispurpose,a vdiagram study was carried out and 25 studentsampled from education faculty chemistry department that consisting of 4th grade students who succeed Chemistry Laboratory course. These students were interviewed and the results were evaluated and compared with the classical laboratory reports, it was investigated whether the diagram provided a real learning environment.
\end{abstract}

Key words: V-diagram, Physical chemistry laboratory, Chemical kinetic, 


\section{Giriş}

Bilim, geçmişteki insanların bilgi birikimlerini günümüzinsanlarına çeşitli yollarla aktarmaları sonucu günümüze kadar gelişerekulaşmıştır (Durak 2007).Teknoloji; bilimin insanlığın hizmetine sunulmuş şeklidir. İnsanlar teknoloji sayesinde bilimi uygulamaya geçirebilmişlerdir.Teknolojinin temelinde ise laboratuvarlar yatmaktadır. Laboratuvarlar teknolojinindoğduğu yerlerdir. Öğrencilere temel olarak çok iyi birfen eğitimi verilmelidir. Bu eğitim laboratuvar uygulamalarıyla desteklenmelidir.Öğrencilerin fen bilimlerine olan ilgilerinin ve becerilerinin arttırılması fen bilimlerinisoyut olmaktan çıkararak öğrencilerin duyu organlarına hitap eder bir bilim haline getirmeklemümkün olur. Özellikle bazı bilim dalları soyut bilgiler ve karmaşık denklemlerle yoğrularakpopüler olmaktan çıkarılmakta böylece öğrencilerin ilgisini çekecek yerde korkulan veçekinilen bir bilim dalı haline gelmektedir.Fen bilimlerinden biri olan kimya, öğrenciler için daha çok soyut kavramların yeraldığı ve bunların birbirleriyle ilişkilerinin incelendiği bir bilim dalıdır. Oysaki kimya somutanlamda ne kadar iyi işlenirse o derece yararlı ve kalıcı olmaktadır. Kimyayı öğrencileryaparak ve yasayarak öğrenmelidirler (Nakipoğlu 2000). Bu şekilde öğrenciler öğrenme olayına aktif olarakkatılmalıdırlar.Laboratuvarlar öğrencilerin sadece el becerilerini geliştirdikleri yerler değildir. Laboratuarlarteorik derslerin tamamlayıcısı ve etkin öğrenmenin sağlandığı önemli mekânlardır. Öğrencilerteorik ders ile laboratuvar çalışmaları arasında bağlantı kurabildikleri ölçüde ilgili dersi etkinbir şekildeöğrenmiş olurlar.Laboratuvarlar etkin öğrenmenin sağlandığı ortamlar olmalıdırlar.Laboratuvar çalışmalarında uygulanan yöntemler öğrenciyi düşünmeye sevk etmeli teorik bilgileri ileuygulamalar arasında bağlantı kurmasını sağlayarak etkin öğrenmeyi oluşturmalıdır.Laboratuvarçalışmalarının öğrencilerde amaçlanan hedef davranışlarıoluşturupoluşturmadığınailişkinçalışmalar incelendiğinde klasik laboratuvar yönteminin amaçlananhedef davranışları öğrencilere kazandırmada bazı aksaklıklar gösterdiği 
görülmüştür. Klasiklaboratuvar çalışmalarında deneyden önce sınav yapılır ardından deneye geçilir var olanimkân ölçüsünde öğrenciler ya tek baslarına ya da grup halinde deneyi yaparlar. Deneyyapıldıktan sonra ilgili deneyle alakalı öğrencilerin deney raporu hazırlamaları istenir.Hazırlanan deney raporları ise belli bir standartta bilgi içermemektedir. Öğrencilerin deneyraporları birbirinden farklı olmaktadır. Bu farklılık hem nitelik olarak hem de nicelik olarakgörülmektedir. Yapılan çalışmalar uygulanan bu yöntemin öğrencide bazı olumsuz davranışve tutumlara neden olabileceğini göstermektedir. Öğrenciler içerisinde büyük bir bölümülaboratuvar çalışmalarında uygulanan deney raporu hazırlama yönteminin yararınınolmadığını düşünmekte hatta bazıları deneyi boş yere yaptıkları hissine bile kapıldıklarınıbelirtmektedirler. Burada ki problemin deneyi yaptıktan sonra amaçlanan hedef davranışlarındeney raporu yöntemi ile kazandırılamamasından kaynaklandığı söylenebilir. $\mathrm{Bu}$ nedenlelaboratuvar çalışmalarında uygulanan yöntemler özellikle klasik deney raporu hazırlamayöntemi incelenerek sorunlar tespit edilmeli ve giderilme yolları araştırılmalıdır. Yapılançalışmalarda sorunlar belirlenmiştir. $\mathrm{Bu}$ sorunların en önemlileri öğrencilerin bu yöntemledüşünmektenuzaklaștıkları ve teorik ders ile uygulama arasında bağlantı kuramadıklarıdır (Durak, 2007).

Yapılan çalışmalar incelendiğinde bu sorunların giderilmesi için geliştirilen vdiyagramıyönteminin yararlı olabileceği görülmektedir.Yapılan çalışmalarda v-diyagramı yöntemiyle öğrenci klasik deney raporuhazırlama yönteminde karşılaştığı birçok problemi çözebilmektedir. Özetle öğrenci v-diyagramınıkullandığında teorik ders ile uygulaması arasında bağlantı kurabilmekte, yaptığıişlem ile ilgili düşünmek ve araştırma yapmak zorunda kalmakta, sahip olduğu teorik bilgileridaha kolay özümsemektedir. Bunun sonucunda da laboratuvarların etkin öğrenmeninsağlandı̆̆ı ortamlar haline geldiği belirtilmektedir. Fen Bilimlerinin önemli bir dalı olankimya bilimi de etkin olarak öğrenilmesi gereken bilim 
dallarından biridir. Kimya bilimininönemli bir alt dalı olan kimyasal kinetik; kimyasal tepkimelerin hızları ile mekanizmalarınıinceleyen bilim dalıdır.

Kimyasal kinetik içerdiği konular itibariyle soyut bilgileri büyükoranda içinde barındırmaktadır. Soyut bilgilerin fazlaca olması ise kimyasal kinetik ile ilgiliyapılan laboratuvar çalışmalarının önemini bir kat daha arttırmaktadır. Genel olaraklaboratuvar çalışmalarındakarşılaşılan sorunlarla kimyasal kinetik ile ilgili laboratuvar çalışmalarında da karşılaşılmaktadır. Bu sorunların giderilmesi için laboratuvar çalışmalarındauygulanan vdiyagramı yönteminin başarılı olabileceği düşünülmektedir.Bu çalışmamızda ilk önce genel olarak laboratuvar çalışmalarındakarşılaşılan sorunlarbelirlenmiş, ardından bu durumun kimyasal kinetik deneylerini içerisinde bulunduranfizikokimya laboratuvarlarında nasıl olduğu incelenmiştir. Daha sonra belirlenen sorunlarıngiderilmesi için v-diyagramı kullanılarak bu sorunlara v-diyagramının etkisi araştırılmıştır.

\section{V-diyagramı}

V-diyagramı Gowin ve öğrencileri tarafından laboratuvarda bilginin daha iyi anlaşılıp yapılandırılması amacıyla, 1970'li yıllarda eğitim alan yazınına kazandırılmıştır. Bu diyagram ile Gowin, öğrencilerin teorik bilgi ile laboratuvar çalışmaları arasındailişki kurmalarını sağlayarak, laboratuvar raporlarının daha anlaşılabilir ve yararlı hale getirilebileceğini savunmuştur(Novak veGowin, 1984).

Fen eğitiminde v-diyagramının anlamlı öğrenmeyi kolaylaştıran, biliş üstü düşünme/öğrenmeyi öğrenme becerilerini geliştiren araçlardan birisi olduğu yapılan çalışmalardabelirtilmiştir(Passmore, 1998). Okebukola (1992), fen ve matematik öğretmenlerinin biliş üstü öğrenme araçları olarak V-diyagramı ve kavram haritalarının etkiliğine yönelik tutumlarını araştıran bir çalımda yapmıştır. Bu çalışmada öğretmenlerin, 
kavram haritalarını ve $\mathrm{V}$ diyagramlarını, kavram öğretimini kolaylaştıran etkili üst düzey bilişsel araçlar olarak algıladıklarını belirlemiştir(Okebukola, 1992).

Roth ve Browen (1993), V-diyagramının öğrencilere bilgilerini daha iyi organize etme, daha etkili bir biçimde araştırma ve öğrenmek için ana hatlar oluşturmada yardımcı olduğunu belirtmişlerdir. Ayrıca öğrencilerin kendi öğrenmelerinin kontrolünü ellerinde bulundurdukları ve böylece V-diyagramını kullanmanın kendilerini daha iyi hissetmelerini sağladığını ifade etmişlerdir(Roth ve Browen, 1993). Roth ve Roychoudhury (1993), İlköğretim fen eğitiminde işbirlikli öğrenme ortamlarında öğrencilerin fizik konularını öğrenmelerinde kavram haritalarının ve V-diyagramının etkililiğine yönelik yaptıkları araştırmalarında; bu araçların kullanımı sırasında, öğrencilerin etkin grup çalışmaları içerisine girdiklerini ve bu sırada devamlı tartışarak deneyde amaçların ne olduğu ve neyi öğrenmelerinin gerektiğini de sorguladıklarını gözlemlemişlerdir.

Nakhleh (1994), özellikle “Genel Kimya Laboratuvar” derslerinde temel amacin “anlamlı öğrenmeyi arttırmak, bilginin yapılandırılması işlemine öğrenciyi aktif olarak katmak ve öğrencilere kendi öğrenmeleri için sorumluluk vermek ve bu konuda cesaretlendirmek" olması gerektiğini vurgulayarak bu amaçla V-diyagramı ve kavram haritaları gibi araçlardan yararlanılması gerektiğini ileri sürmüştür. Ault, Novak ve Gowın, (1984) v- Diyagramının ölçme-değerlendirme amacıyla da kullanılabileceğini belirtmektedirler.

Passmore (1998), Radyoloji eğitiminde teknoloji laboratuarları uygulamaları sırasında öğrencilerin kavram yanılgılarını gidermede ve anlamlı öğrenmelerini kolaylaştırmada kavram haritalarının ve V-diyagramının etkiliğiniaraştırmıştır. Sonuç olarak, kavram haritalarını ve Vdiyagramını kullanan öğrencilerin biliş üstü düşünme stratejilerini geliştirdikleri, çalıştıkları bilginin kavramsal, ilişkisel ve hiyerarşik yapısını, doğasını incelemeleri nedeniyle anlamlı bir şekilde öğrendiklerini ve kavram yanılgılarını azalttıkları gözlemlenmiştir. 
Nakiboğlu ve Meriç (2000) çalışmalarında V-diyagramının laboratuvar öncesi ön hazırlık sırasında öğrencileri araştırmaya sevk ettiğini, laboratuvar raporu hazırlamada bir standart sağladığını ve kavram öğrenimine yardımcı olduğunu gözlemlemişlerdir. Nakiboglu, Benlikaya ve Karakoç, (2001) orta öğretim kimya derslerinde laboratuvar uygulamalarının daha etkili yürütülmesinde ve anlamlı öğrenme sürecinde V-diyagramının etkili olduğunu vurgulamaktadirlar.

Roehrıg, Luftalve Edwards, (2001) V-diyagramının oluşturulması sırasında, öğrencilerin bilimsel bilginin nasıl oluştuğunu anladıklarını ve birlikte çalışmalar sonucunda iletişim becerilerinin arttığını gözlemlemişlerdir. Afamasaga-Fuata’i (2004) üniversite öğrencilerinin ileri matematik konularını anlamalarında kavram haritaları ve V-diyagramının etkililiğini araştırdığı örnek olay çalışmasında bu araçların öğrencilerin konuları anlama ve öğrenme süreçlerini kolaylaştırdığınıgözlemlemiştir.

Sarıkaya, Selvi ve Yakışan(2004) V-diyagramlarının hayvan fizyolojisi laboratuvarı konularını öğrenmedeki etkisi konulu araştırmalarında, bu aracın öğrenci başarısını anlamlı derecede arttırdığını ortaya koymuşlardır.Ahlberg, Aamsmaave Dillon, (2005)Hizmet öncesi öğretmen eğitiminde ev ekonomisi ders programının geliştirilmesine yönelik 4 yıl süreli yürüttükleri eylem araştırmalarındaaraştırma sürecinin planlanması, yürütülmesi ve değerlendirilmesinde kavram haritaları ve V-diyagramını kullanmışlar ve bunların öğretmen adaylarının düşünme ve profesyonel gelişimlerini ilerletmede etkili olduklarını gözlemlemişlerdir.

Özsoy (2004) tarafından yapılan çalışmada V diyagramları ve kavram haritaları fonksiyonlar konusunun öğretiminde kullanılmış ve bunların matematik eğitiminde anlamlı öğrenmeyi sağlamadaki etkililiği tartışılarak, konu ile ilgili diyagram örnekleri sunulmuştur. Case (2006) V diyagramlarının bilimsel araştırma sürecinde öğrencilerin süreç içerisinde 
nerede olduklarını ve nasıl ilerlemeleri gerektiğini gösteren bir yol haritası görevi gördüğünü, iletişime yardımcı olduğunu; öğretmenler içinse araştırma sürecinin anlamlı bir öğrenme ortamına dönüşmesine yardımcı olan grafiksel bir rehber olduğunu belirtmiştir.

Sonuç olarak V diyagramları; bilginin nasıl ispat edildiğini ve bu ispatta kullanılan kayıtların nasıl yorumlanacağını göstermede, kavram yanılgılarını belirlemede ve gidermede, öğrencilerin ilgisini konuya çekmede, öğrenmeyi teori ve uygulamayla bir arada götürmede sistematik bir yolla çözüm sunmayı kolaylaştıran laboratuvar uygulama ve değerlendirme araçlarıdır.

\section{V-diyagramı nasıl organize edilir?}

V-diyagramında kavramsal ve deneysel bölümlerde yer alan baslıklar: odak sorusu, araç ve gereçler, teoriler ve ilkeler, kavramlar, bilgi iddiaları ve deneysel iddialar, veri dönüşümleri ile kayıtlardır. V-diyagramı hazırlanırken genel olarak aşağıdaki sıra takip edilmelidir:

Yöntem olarak V-diyagramı 3 ana parçaya bölünebilir. Büyük bir V harfi çizimi ile başlayan diyagramın ortasında odak sorusu yer alır. Odak sorusu, sol tarafta yer alan kavramsal kısım ile sağ taraftaki yöntem kısmı ile bağlantılıdır ve bir geçiş sağlar. Genellikle sol tarafı ve merkezi; laboratuvar öncesi etkinlik olarak ve sağ tarafı ise deneyden sonra doldurulan Vdiyagramı ve bölümlerinin genel bir gösterimi Şekil 1'de verilmiştir. İşbirlikçi öğrenme Yöntemine göre öğrenciler tarafından grup çalışması yapılarak doldurulan diyagram, anlamlı öğrenme yolunda ilk adımı atmalarını sağlar. Bunun yanında, odak sorusu veya sorularını oluştururken, bilgilerini tekrar kullanmalarını sağlayarak, öğrenmeyi pekiştirir. 


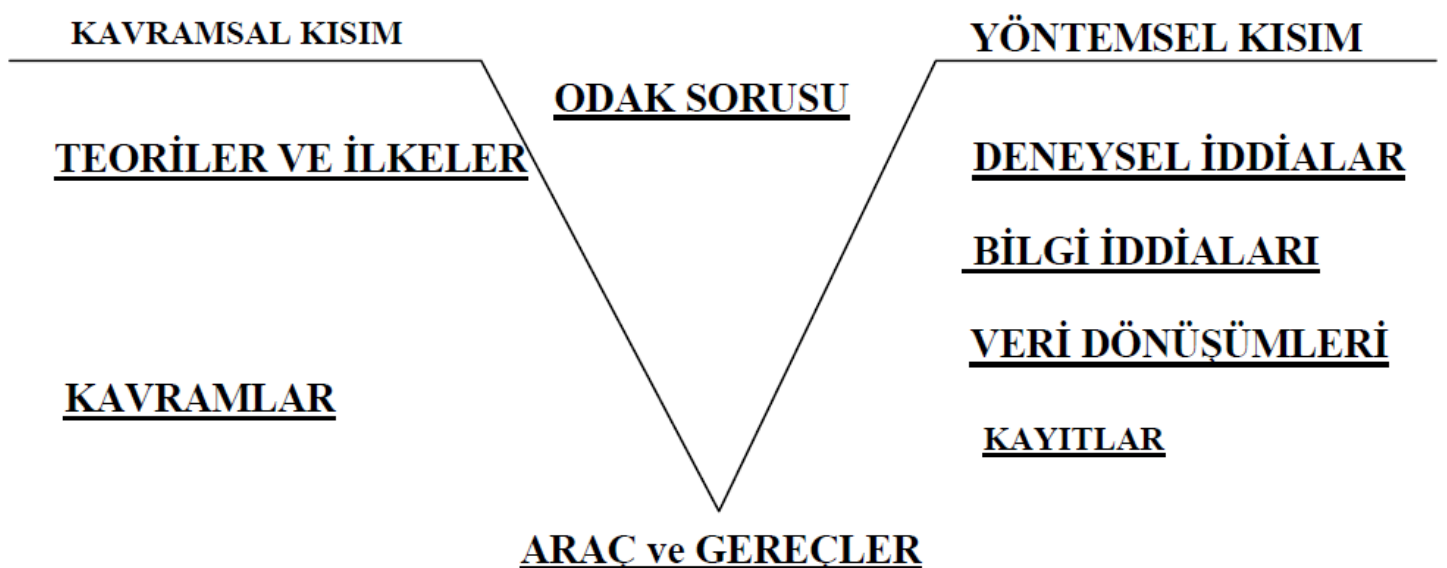

Şekil 1. V-Diyagramı oluşum şeması

Diyagramda yer alan ve öğrencinin dolduracağı kısımlarda neler bulunması gerektiğini su şekilde açıklayabiliriz:

Odak sorusu: Odak sorusu teoriden pratiğe bir geçiş olarak düşünülebilir. Maddeler ve araştırmanın ana olayı ile ilgilidir ve bunları tanıma ve kavrama ile baslar. Odak sorusu iki taraf ile de bağlantılı olmalıdır. Odak sorusu bir veya en fazla iki tane olabilir ve araştırmanın bazı anahtar kavramlarını içerebilir, araştırmadaki olayları belirtir. Bir yerde deneysel olarak kanıtlanması gereken bir soru, deneyde ulaşılan bir sonuç, bir anahtar kavram veya denemenin amacını ortaya koyan bir soru olabilir.

Araç ve gereçler: Deney süresince kullanılan, deneye özgü etkili araç ve gereçlerin bir listesinin bulunduğu araç ve gereçler kısmı, v-diyagramının tabanında v-şeklinin alt sivri ucunda yer alır.

Teoriler ve ilkeler: Deneyin konusuyla ilgili teori ve ilkeler bu k1sma yazılır. Teori ve ilkeler deneyin anlaşılması için yol gösterici olup, deneyde hangi aletleri kullanacağımızı da belirlememize yardımcı olur. 
Kavramlar: Deney konusu ile ilgili bilinmesi gereken kavramları ve bunlar ile ilgili terimler, ifadeler ve semboller bu kısma deneyden önce yazılır ve böylece öğrenci deneye başlamadan, konu ile ilgili kavramları öğrenmiş olur.

Bilgi iddiası ve deneysel iddialar: Bilgi iddiaları odak sorularına cevaplardır. Yeni araştırma ve iddialara yön verebilecek yeni sorular önerebilirler. Bu iddialar, odak sorusuna yön veren kavramsal ve yöntemsel bilgiyle tutarlı olmalıdır. En geçerli iddialar, odak sorusuna cevap verenler ya da sağlayanlardır. Aynı şekilde bu iddiaların deneyle daha ilgili olanları yani uygulamaya yönelik olanları ise deneysel iddialar olarak bu kısımda yer alır.

Veri ve bilgi dönüşümleri: Dönüşümler aslında olayların daha başarılı ve anlamlı bir şekilde yeniden sunulan, yeniden düzenlenen veya düzeltilen kayıtlarıdır. Bunlar karşılaştırmalar, farklar, tablolar, grafikler, çizimler, istatistikler ve değer yargıları gibi özel bilgilerden oluşmaktadır. Verilerin bu şekilde yeniden sunumları öğrencinin odak sorusuna daha rahat ve daha kolay bir şekilde cevap bulabilmesine izin vermektedir.

Kayıtlar (Ölçümler, sonuçlar, gözlemler): Deney süresince elde edilen tüm sonuçlar, ölçümler ve gözlemler bu kısımda ortaya konulacaktır.

Nakiboğlu, Benlikaya ve Kalın, (2002) yapmış oldukları çalışma sonucunda vdiyagramının kullanımı ile ilgili su sonuca varmışlardır. "Kimya laboratuvarlarında, vdiyagramlarının deney raporu olarak kullanılması, öğrencilerin yanlış kavramlarının kolay bir şekilde belirlenmesinde öğreticilere ve konuyu öğrenmede ise öğrencilere katk1 sağlayabilir”.

Tatar, Korkmaz ve Şaşmaz Ören (2007)yapmıș oldukları çalıșma sonucunda vdiyagramı ile ilgili su görüşleri ileri sunmuşlardır. "V-diyagramı öğrencilerin teorik ve pratik bilgilerini bütünleştirmektedir. Bu araçların kullanıldığı laboratuvarlarda ön bilgi yeni bilginin yapılandırılmasında temeldir. Öğrenciler ön bilgilerini gözden geçirerek elde ettikleri yeni 
bilgilerini günlük hayatlarında kolaylıkla kullanabilir, yeni bakış açıları geliştirerek daha detaylı bilimsel araştırmalara yönelebilirler”(Tatar ve dĭg., 2007, s.87)..

Nakiboglu ve Meriç, (2000) yapmış oldukları çalışmalarında v-diyagramının faydaları ile ilgili su görüşleri ileri sunmuşlardır; "Laboratuvar öncesi ön hazırlığı sırasında öğrencileri araştırmaya sevk eder, rapor hazırlamada bir standart sağlar, düşünerek öğrenmeye neden olduğundan anlamlı ve kalıcı bir öğrenme sağlar, öğrencilerin soru sorma yeteneğini geliştirerek öğrencinin konuyu daha iyi öğrenmesini sağlar, öğrencilerin grup çalışması yapmasını sağlayarak tartışma yeteneklerini geliştirir”(Nakiboglu ve Meriç, 2000, s.74).

Meriç (2003) yapmış olduğu çalışma sonucunda v-diyagramı kullanımı ve faydaları ile ilgili su önerilerde bulunmuştur; "V-diyagramı, kavram öğretiminde, yanlış kavram tespiti ve giderilmesinde, oluşturmacı yaklaşımda, problem çözme yönteminde, getireceği yararlar arasında bir araç olarak derslerde ve bundan sonraki tüm çalışmalarda ülkemizde mutlaka dikkate alınmalıdır” (Meriç, 2003, s.147). 


\section{Yöntem}

\section{Araștırmanın Modeli}

Araştırmada alan tarama modeli kullanılmıştır.

\section{Örneklem}

Genel kimya laboratuvarlarının öğrenmeye olan katkısının nasıl olduğunun belirlenmesi amacı ile oluşturulan 227 kişilik örneklem grubu, bir devlet üniversitesindeki, Eğitim Fakültesi, Kimya Bölümü 3., 4., 5., sınıf öğrencileri, Fen Bilgisi Öğretmenliği 2., 3., sınıf öğrencileri ve Fen Edebiyat Fakültesi Kimya Bölümü 2., 3. ve 4., sınıf öğrencilerinden oluşmaktadır.

\section{Veri Toplanması}

Anketyolu ile yapılan veri toplama işleminde, 1 tanesi açık uçlu, 10 tanesi çoktan seçmeli olmak üzere toplam 11 soruluk bir anket uygulanmıştır.

\section{Veri Analizi}

Veri çözümlemede doğrudan istatistiksel çözümleme uygulanarak, sonuçlar frekans dağılımı ve yüzde olarak verilmiştir. 


\section{Bulgular}

1 numaralı anket sorusu olan Genel kimya dersinin etkin bir şekilde ögrenilebilmesi için laboratuvarlarda yapılan deney sayısını yeterli buluyor musunuz? sorusuna öğrencilerin \%76'sı genel kimya laboratuvar çalışmalarında yapılan deney sayısını yetersiz bulurken \%24'ü ise yapılan deney sayısının yeterli olduğunu belirtmektedir.

2 numaralı anket sorusu olan Genel kimya laboratuvarında yapılan deneylerin gereksiz olduğunu düşündünüz mü??sorusuna verilen yanıtlar incelendiğinde öğrencilerin \%85'i genel kimya laboratuvar uygulamalarında yapılan deneylerin gerekli olduğunu belirtirken bunun yanında öğrencilerin \%15’i ise yapılan deneylerin gereksiz olduğunu belirtmektedir.

3 numaralı anket sorusu olan Deneyi yaptıktan sonra teorik dersleri anlamada ve pekiştirmenizde ne derecede yararını görüyorsunuz? Sorusuna öğrencilerin \%21'i deneyi yaptıktan sonra teorik dersleri anlamada ve pekiştirmede çok yarar gördüğünü belirtirken, \%8'i hiç, \%71'i ise kısmen yarar gördüğünü belirtmiştir.

4 numaralı anket sorusu olan Gördüğünüz derslerle laboratuvarın bağlantısını ne derece iyi kurabiliyorsunuz? Sorusuna öğrencilerin ancak \%15'i gördüğü derslerle laboratuvarın bağlantısını çok iyi kurduğunu belirtirken, \%13'ü hiç, \%72'si ise kısmen bağlantı kurabildiğini belirtmiştir.

5 numaralı anket sorusu olan Genel kimya laboratuvarında bugüne dek hazırladığınız deney raporları size ne derecede yararlı oldu veya ne derecede yararını gördünüz? Sorusuna öğrencilerin ancak \%15'i bugüne dek hazırladığı deney raporlarından çok yarar gördüğünü belirtirken, \%37'si hiç, \%48'i ise kısmen yarar gördüğünü belirtmiştir.

6 numaralı anket sorusu olan Bir deney raporu sizce deneyi ne derecede iyiözetleyebilmektedir? Sorusuna öğrencilerin verdikleri yanıtlara göre sadece \%22'si bir deney 
raporunun deneyi çok iyi özetleyebildiğini belirtirken, öğrencilerin \% 59’u kısmen özetleyebildiğini , \%19’u ise hiç özetleyemediğini belirtmektedir.

7 numaralı anket sorusu olan Deney sonrası hazırlanan deney raporlarını bos yere hazırladı̆̆ınız hissine kapılıyor musunuz? Sorusuna öğrencilerin verdikleri yanıtlarda görüldüğü gibi öğrencilerin \% 64’ü deney sonrası hazırladığı deney raporunu bos yere hazırladığını düşünüyorken öğrencilerin \% 36'sı ise deney sonrası hazırladığı deney raporunu bos yere hazırlamadığını düşünmektedir.

8 numaralı anket sorusu olan Laboratuvarda yapılan deneylerle ilgili klasik deney raporu hazırlamanın faydalı olduğuna inanıyor musunuz? Öğrencilerin \%42'si klasik deney raporu hazırlamanın faydalı olduğunu düşünürken, $\% 58$ 'i ise klasik deney raporu hazırlamanın faydalı olmadığını düşünmektedir.

9 numaralı anket sorusu olan Uygulaması olan teorik dersleri ögrenmede deney raporlarından yararlanıyor musunuz? Sorusuna öğrencilerin \%34'ü teorik dersleri öğrenmede deney raporlarından yararlandığını belirtirken, \%66’sı ise teorik dersleri öğrenmede deney raporlarından yararlanmadığını belirtmektedir.

10 numaralı anket sorusu olan Deney yapmadan önce yapacağınız deneyle ilgili ön çalışma yapıyor musunuz? Sorusuna öğrencilerin \%67'si deney yapmadan önce ön çalımsa yaptığını belirtirken, \%33'ü ise deney yapmadan önce ön çalışma yapmadığını belirtmektedir.

Laboratuvar çalışmalarının öğrenmeye katkısının ne olduğunun belirlenmesi amacıyla öğrencilere ilgili çoktan seçmeli anket sorularının sorulmasının ardından "deney raporlarında hangi baslıkların ve nelerin yer alması" ile ilgili açık uçlu bir soru sorulmuştur. Bu soruya, öğrencilerin verdiği cevaplar etiketlenerek aşağıdatablo-1 degösterilmiştir. 


\section{Tablo-1}

\section{1 numaralı anket sorusu verileri}

\begin{tabular}{lcc}
\hline & Öğrenci sayısı (f) & Yüzde değeri (\%) \\
\hline 1- Deneyin adı & 11 & 53 \\
2- Deneyin amacı & 52 & 29 \\
3- Teorik bilgi & 65 & 34 \\
4- Deneyin yapılışı & 78 & 7 \\
5- Günlük hayatla bağlatı & 17 & 18 \\
6- Araç-gereç & 40 & 4 \\
7-Hesaplamalar & 10 & 4 \\
8- Şekil çizimi & 9 & 27 \\
9- Sonuç & 61 & 33 \\
10- Yorum & 76 & 9 \\
* Teorik bilgi gereksiz & 21 & 14 \\
* Deney raporu gereksiz & 32 & 18 \\
*Cevap yok & 40 & \\
\hline
\end{tabular}




\section{Tartışma ve Sonuç}

Bu çalışmada, öğrencilerin fen bilimlerinde önemli öğretim tekniklerindenbiri olan alan taraması yöntemine göre kimya laboratuvarlarında, yaptıklarıuygulamalarının öğrenmelerine katkısının ne olduğu incelenmiştir.Bu amaçla hazırlanan anket sorularına verilen yanıtlar bulgular kısmında yüzde dağılım şeklinde incelenmiştir.

Laboratuvarlar soyut ve karmaşık bilgilerin somutlaştırılarak daha iyi anlaşıldığı mekânlardır.Ĕ̆er öğrenci teorik derste öğrendiği soyut bilgilerini laboratuvar çalışmalarında kullanıyorama bu bilgileri daha sonra kullanmıyor ise böyle bir çalışmanın öğrenme sağladığınısöylemek güçtür. Çünkü laboratuvar öğrenmenin tamamlandığı yerler ise laboratuvar çalışmalarından daha sonrada faydalanılması gerekmektedir. Burada sorunun büyük birbölümünün kullanılan klasik rapor hazırlama yönteminden kaynaklandığını söyleyebiliriz.Sonuç olarak kimyasal kinetik dersi ile ilgili öğrencilerin öğrenme problemlerininolduğu, bu problemlerin klasik deney raporu hazırlama yöntemiyle tam olarak çözülemediğini veöğrencilerin laboratuvar çalışmalarında amaçlanan hedef davranışlaraulaşmada zorluklar yaşadıkları söylenebilir.

Nakiboğlu ve ark. nın(2000) yapmış oldukları çalışmada, öğrencilere “Sizce bir deneyraporu hangi bölümleri mutlaka içermelidir?” şeklinde bir soru yöneltmişlerdir. Bu soruyaverilen yanıtlara göre öğrencilerin klasik deney raporundan dişında farklı bölümlerbelirtmemişlerdir. Bu çalışmada öğrencilerin deney raporunun içeriği ile ilgili çok fazla fikirleri olmadığı belirtilmiştir.

Görüldüğü gibi Nakiboğlu ve ark.(2000) tespit ettiği sorunbizim çalışmamızda da aynı şekilde tespit edilmiştir. 
Nakiboğlu ve ark.(2002) yapmış oldukları çalışmasonucunda v-diyagramının kullanımı ile ilgili su sonuca varmışlardır. "Kimya laboratuvarlarında, v-diyagramlarının deney raporu olarak kullanılması, öğrencilerinyanlışkavramlarının kolay bir şekilde belirlenmesinde öğreticilere ve konuyu öğrenmede ise öğrencilere katkı sağlayabilir.” Yapılan bu çalışmada belirtilen v-diyagramı faydaları bizim yaptığımız çalışmada da saptanmıştır.

Tatar ve ark.(2007) yapmış oldukları çalışma sonucunda v-diyagramı ile ilgili su görüşleri ileri sunmuşlardır. "V-diyagramı öğrencilerin teorik ve pratik bilgilerini bütünleştirmektedir.Bu araçların kullanıldığı laboratuvarlarda on bilgi yeni bilginin yapılandırılmasında temeldir. Öğrenciler on bilgilerini gözdengeçirerek elde ettikleri yeni bilgilerini günlük hayatlarında kolaylıkla kullanabilir, yeni bakış acıları geliștirerek daha detaylı bilimsel araştırmalarayönelebilirler.”

“V-diyagramı bilimsel araştırmayöntemlerini takip etmeleri içinöğrencilere kılavuzluk edecek eğitsel bir araçtır. $\mathrm{Bu}$ araçöğrencilere tanıtılarak, fen laboratuarlarında sıklıkla kullanılmalıdır."

Yine Nakiboğlu ve ark.(2000) yapmış oldukları çalışmalarında v-diyagramının faydaları ile ilgili şu görüşleri ileri sunmuşlardır; “ Laboratuvar öncesi on hazırlığı sırasında öğrencileriaraştırmaya sevk eder, rapor hazırlamada bir standart sağlar, düşünereköğrenmeyeneden olduğundan anlamlı ve kalıcı bir öğrenme sağlar, öğrencilerin soru sorma yeteneğini geliştirereköğrencinin konuyu daha iyi öğrenmesini sağlar, öğrencilerin grup çalışması yapmasını sağlayarak tartışma yeteneklerini geliştirir.”

Meriç (2003) yapmış olduğu çalışma sonucunda v-diyagramı kullanımı ve faydaları ile ilgili su önerilerdebulunmuştur; “ V-diyagramı, kavram öğretiminde, yanlış kavram tespiti ve giderilmesinde, oluşturmacıyaklaşımda, problem çözmeyönteminde, getireceği yararlar 
arasında bir araç olarak derslerde ve bundan sonraki tümçalışmalardaülkemizde mutlaka dikkate alınmalıdır."

Laboratuvar çalışmaları öğrenciyi düşünmeye sevk etmeli, sahip olduğu teorik bilgilerigözden geçirmesini sağlayarak deneysel çalışmalarla anlamlı ilişkiler kurmasınısağlayabilmeli, öğrencide bilimsel tutum ve davranışlarıgeliştirmeli, bilimsel çalımsa motivasyonuoluşturmal1, gerçek hayatla ilgili problemlerin çözümünde sahip olduğu bilgilerikullanmasını sağlayacak nitelikte olmalıdır. Burada önemli olan laboratuvar çalışmalarındaöğrenciye tüm bu davranışları hangi yöntemi kullanarak kazandırabileceğimizdir. Burada v-diyagramıetkili bir öğretim yöntemi olarak öne çıkmaktadır.

Yaptığımız çalışma sonucunda elde edilen veriler yardımıyla v-diyagramı ile ilgili su görüş ve öneriler sunulabilir.Yaptığımızçalışmadaki bulgular dikkate alındığında vdiyagramının faydalarını şuşekilde sıralayabiliriz;

- Teorik derslerde anlaşılması güç olan kavramları anlamaya yardımcı olur.

- Zaman kazandırır, deney raporuna göre çok daha kısa sürede hazırlanabilir.

- Teorik ders ile deneysel çalışmalar arasında daha kolay bir ilişki kurulmasını sağlar.

- Deney raporları için bir standart sağlayarak daha objektif değerlendirme sunar.

- Sahip olunan bilgilerin sinıflandırılmasını, hangi bilginin nerde nasıl kullanılacağınınöğrenilmesini sağlar.

- Deney öncesi hazırlık gerektirir.

- V-diyagramı deney raporu içerisinde yer alan fazla ve kafa karıştıran bilgileri içermez.

\section{Makalenin Bilimdeki Konumu (Yeri)}

Orta Öğretim Fen ve Matematik Alanları Bölümü / Kimya Eğitimi Anabilim Dalı

\section{Makalenin Bilimdeki Özgünlüğü}


Literatürde mevcut çalışmalar incelendiğinde, Kimya laboratuvarlarında V-diyagramı kullanımının çok sınırlı olduğu görülmektedir. Kimya laboratuvar derslerinde yapılan sınavlara ve hazırlanan raporlara alternatif olabilecek yeni yöntemlerden birinin V-diyagramı olduğu düşünülerek anlaşılması güç olan kimyasal kinetik deneylerinde uygulanabilirliği incelenmiştir.

\section{Kaynakça}

Afamasaga-Fuata'i, K. (2004). Concept maps \&vee diagrams as tools for learning new mathematics topics. Concept Maps: Theory, Methodology, Technology Proc. of the First Int. Conference on Concept Mapping Pamplona, Spain 2004

Ahlberg, M., Aamsmaa, P., Dillon, P.(2005). Education for sustainable living: Integrating theory, practice, design and development. Scandinavian Journal of Educational Research, 49(2), 167-186.

Ault, R. C.,Novak, J. D., Gow1n, D.B. (1984). Constructingveemapsforclinicalinterviews on moleculeconcepts. ScienceEducation, 68 (44), 441-462.

Case, S. B. (2006).

PathfinderScienceL.L.Chttp://stemtec.org/piconf/Proceedings/Papers/Case.doc adresinden alınmıștır.

Durak H. (2007). Fizikokimya Laboratuvarlarında V-diyagramı kullanımı ve uygulamaları.(Yayınlanmamış yüksek lisans tezi)Yüzüncü Yıl Üniversitesi, Fen Bilimleri Enstitüsü. Van.

Meriç, G. (2003). Bir Değerlendirme ve Laboratuvar Aracı Olarak V-Diyagramı'nın Tarihi, Kullanımı ve Fen Eğitimine Sağlayacağı Katkılar Üzerine Bir inceleme. Pamukkale Üniversitesi Ĕ̈itim Fakültesi Dergisi.1 (13), 147.

Nakhleh, M. B. (1994). Chemical education research in the laboratory environment: How can research uncover what students are learning? Journal of Chemical Education, 71(3), 201-205.

Nakiboğlu, C.,Benlikaya, R., Kalın, S. (2002). Kimya ögretmen adaylarının kimyasal kinetik ile ilgili yanlıs kavramlarının belirlenmesinde v-diyagramının kullanılması. Elde edilebilecek elektronik kaynak: http://www.fedu.metu.edu.tr/ufbmek5/b_kitabi/PDF/Kimya/Bildiri/t179d.pdf adresinden alınmıştır. Erişim tarihi: 2007. 
Nakiboglu, C.,Benlikaya, R., Karakoç, Ö. (2001). Ortaögretim kimya derslerinde v-diyagramı uygulamaları. Hacettepe Üniversitesi Egitim.Fakültesi Dergisi, 21(1) 97-104.

Nakiboglu, C., Meriç, G. (2000). Genel kimya laboratuvarlarında v-diyagramı kullanımı ve uygulamaları. BAÜ Fen Bilimleri Enstitiisü Dergisi, 2 (1), 58-75.

Novak, J. D.,Gowin D. B. (1984). Learning how toLearn. Cambridge, England, Cambridge UniversityPress.

Okebukola, P. A. (1992). Attitude of teachers towards concept mapping and vee diagramming as metalearning tools in science and mathematics. Educational Research, 34(3), 201215 .

Özsoy, N. (2004). Kavram haritalarının ve vee diyagramlarının fonksiyonlar ünitesinin öğretilmesinde ve öğrenilmesinde kullanılması. Gazi Eğitim Fakültesi Dergisi, 24 (2), $15-24$.

Passmore, G. G.(1998). Using the vee diagrams to facilitate meaningful learning andmisconception. Radiologic Science and Education, 4 (1), 11-28.

Roehrıng, G., Luftal, A. L., Edwards, M. (2001). Versatile vee maps. The Science Teacher, 68 (1), 28-31.

Roth, W. M., Browen, M. (1993). The unfolding vee. Science Scope, 16 (5), 28-32.

Roth, W. M., Roychoudhury, A. (1993). Using vee and concept maps in collaborative setting: elementary education majors construct meaning in physical science courses. School Science and Mathematics, 93 (5), 237-244.

Sarıkaya, R., Selvi, M., Selvi, M., Yakısan, M. (2004). V-diyagramlarının hayvan fizyolojisi laboratuvarı konularını öğrenme basarısı üzerine etkisi. G. Ü. Gazi Egitim Fakültesi Dergisi, 24 (3), 341-347.

Tatar, N., Korkmaz, H., \& Şaşmaz Ören, F. (2007). Effective tools as a developing scientific process skill in inquiry-based science laboratories: Vee\& I diagrams. Elementary Education Online, 6(1), 76-92. 


\section{Summary}

Chemistry, one of the sciences, is a scientific discipline in which more intangible concepts take place for students and their relations with each other are examined. If, the chemistry processed much tangible sense, the more beneficial and lasting it is. The students should learn chemistry by practicing and living. In this way, students should actively participate in learning. Laboratories are not the only places where students develop hand skills. Laboratories are complementary to theoretical courses and are important places for active learning. Students will be able to effectively learn the relevant course as much as they can establish link between the theoretical course and laboratory studies. Laboratories should be environments where effective learning is provided, the methods applied in laboratory studies should create effective learning by providing the link between theoretical knowledge and applications by leading students to think. When the studies are examined on whether the laboratory studies have exposed the purposed behaviors in the students, it has been seen that the classical laboratory method shows some obstacles to gaining the purposed behaviors to the students. When the studies are examined, it can be seen that the v-diagram method developed for solving these problems may be useful. Through the v-diagram method, the student can solve many problems encountered in the method of preparing the classical experiment report. In sum, student can establish a link between the theoretical course and its application, think about the activity he has done and have to do research, absorbs the theoretical knowledge more easily when they use the v-diagram. 


\section{Research Method}

In the first part of the study, by using the screening model, the importance of the general chemistry and physicochemistrylaboratoriesin the learning environment is examined. In the second part,the v-diagram is applied on the students by using the experimental model. A questionnaire was prepared by examining the related studies and taking the opinions of the course instructors for the first part of the research. The open-ended questions in the questionnaire were evaluated with the help of course instructors. Population of the research comprise the students in Chemistry Teaching, Science Teaching and Chemistry Departments of the relevant faculties, contain within Turkey's Council of Higher Education. The first sample group of 227 students with the aim of determining the contribution of the general chemistry laboratories to learning comprises the 3rd, 4th, 5th grade students of YüzüncüY1l University, Faculty of Education, Chemistry Department, Science Education Teacher Department, 2nd, 3rd grade students, and 2nd, 3rd and 4th grade students in Chemistry Department of Science Faculty. The second sample group of 77 persons, which was formed with the aim of determining the contribution of physicochemistry laboratories to learning, consists of YüzüncüY1l University, Faculty of Education Department of Chemistry 4th and 5th grade students and 4th grade students of Science Faculty. The third sample group of 20 persons selected as a control group for applying the V-diagram and then for comparison is the 4th grade students of the Faculty of Education, Department of Chemistry, who successfully completed the physicochemistry laboratory course.

\section{Findings}

The students stated that the conceptual part in the v-diagram is of great benefit in learning the concepts related to the subject and that it is related to the experimental part, thus eliminating the misconceptions of the related subjects. Students have stated that the v-diagram 
allows for saving time and makes them use time more efficiently. Students stated that during the filling of the v-diagram, the necessity of using the theoretical knowledge related to the experiment provides a link between the theory course and its applications. Students stated that the use of the v-diagram as a experiment report constitutes a standard among the reports and will provide more objective evaluation. Students stated that the v-diagram helped to classify the information they had because they did not have irrelevant information about experiment, it helped them to learn where and how to use the information obtained and helped them gather together the disordered information they had. Students expressed that due to the conceptual part in the v-diagram had to be filled before the experiment they had to be prepared for the experiment. Relevant with this, a student expressed his opinion as follows; "When the vdiagram is compared with the experiment report, it can be more useful and more efficient than the experiment report due to seeing all findings and information on a single page and creates integrity, the links between findings and theories more successfully established."

\section{Discussion and Results}

Laboratories are places where intangible and complex information is better understood and embodied. It is difficult to say that such a study provides learning if the student uses the intangible knowledge he or she has learned at theoretical course in laboratory practices but does not use this information later. If the laboratories are the places where the learning is completed, it is necessary to make use of laboratory practices afterwards. At this point, we can say that most of the problem arises from the use of classical report preparation method. As a result, it can be said that the students have learning problems in chemical kinetic course, these problems can not be solved completely by the method of classical experiment report preparation, and students have difficulties in reaching the purposed behaviors at laboratory practices. The laboratory practices should lead to students to think, be able to provide students meaningful 
relationships with experimental studies by providing them to look over the theoretical knowledge they have and should develop scientific attitudes and behaviors in the student, create scientific motivation and use the information that they have in real life problems. What is important here is by using which method we can make the students gain all these behaviors in laboratory practices. At this point, v-diagram stands out as an effective teaching method.

As a result of the research we have done, we can present the opinions and suggestions about the v-diagram with the help of the data obtained. Considering the findings of our study, we can list the benefits of the v-diagram as follows;

As a result of the work we have done, we can present the opinions and suggestions about the vdiagram with the help of the data obtained. Considering the findings of our study, we can list the benefits of the v-diagram as follows;

- Helps to understand concepts that are difficult to understand in theoretical courses.

- Saves time, can be prepared much shorter than the experiement report.

- Provides establish link between the theoretical course and the experimental work easier.

- Provides a more objective assessment by providing a standard for experiment reports.

- Classify the information that is gained and learn how to use it.

- Requires pre-examination preparation.

- The V-diagram does not contain excess and confusing information contained in the experiment report. It contains only information and theories to be used in the experiment, leads the student to think with the brief and core information it provides. 